\title{
Intraoperative somatosensory evoked potentials to facilitate peripheral nerve release
}

\author{
[Les potentiels évoqués somesthésiques peropératoires pour faciliter la libération de \\ nerfs périphériques]
}

Jean Corentin Salengros MD, ${ }^{*}$ Pierre Pandin MD, ${ }^{*}$ Frédéric Schuind MD PhD, $†$ Arlette Vandesteene MD PhD*

Purpose: The significance of intraoperative somatosensory evoked potentials (SSEP) monitoring is well known during spinal surgery. This technology could be beneficial during peripheral nerve surgery as well. In order to illustrate potential applications, two cases of successful peripheral nerve release demonstrated by on-line, intraoperative, SSEP are reported.

Clinical and technical features: The first case presents a complex brachial plexus lesion involving two mixed sensorymotor nerves: median and ulnar. The second case involved an entrapment neuropathy of the lateral femoral cutaneous nerve, a pure sensory nerve (meralgia paresthetica). For each patient we elicited specific peripheral nerve SSEP (recorded using bipolar cephalic montage) by stimulating each nerve independently. In each case, during difficult nerve dissection and after having excluded other possible factors of intraoperative SSEP variations, an increase of the SSEP amplitude was observed, and later correlated with favourable patient clinical outcome.

Conclusions: Two cases demonstrate that intraoperative SSEP monitoring may provide an effective tool to guide surgical dissection during peripheral nerve release. This technique has potentially beneficial clinical applications and warrants further investigation.

Objectif : La valeur du monitorage par les potentiels évoqués somesthésiques (PES) pendant une opération de la colonne vertébrale est bien connue. Il peut offrir des avantages pendant la chirurgie des nerfs périphériques. Pour illustrer ses applications possibles, nous présentons deux cas de libération réussie de nerfs périphériques démontrée par les PES peropératoires en ligne.

Caractéristiques cliniques et techniques : Le premier cas concerne une lésion complexe du plexus brachial touchant deux nerfs mixtes sensori-moteurs : médian et cubital. Le second cas porte sur une neuropathie de compression du nerf cutané fémoral latéral, un nerf sensitif (méralgie paresthésique). Pour chaque patient, nous avons suscité les PES du nerf périphérique concerné (enregistrés selon un montage céphalique bipolaire) en stimulant chaque nerf séparément. Dans chaque cas, pendant la dissection difficile du nerf et après avoir exclu tout autre facteur possible de variation des PES peropératoires, une hausse de l'amplitude des PES a été observée et corrélée ensuite avec l'évolution clinique favorable du patient.

Conclusion: Les cas présentés montrent que le monitorage peropératoire par les PES peut guider efficacement la dissection chirurgicale pendant la libération d'un nerf périphérique. II a des applications cliniques potentiellement bénéfiques et devrait être étudié plus avant.

I NTRAOPERATIVE electrophysiological monitoring has been recommended for some time, ${ }^{1}$ and has been considered a safety standard during major spinal ${ }^{2-4}$ or vascular ${ }^{5}$ surgery in order to reduce the risk of surgery-induced lesions on neuraxial structures. Peripheral nerve lesions have also been studied $^{6,7}$ and we introduced recently in our clinical practice a monitoring technique to guide the surgeon during dissection of peripheral nerve structures, including isolated nerves or a nerve plexus. Such monitoring could be relatively easily performed with mixed peripheral nerves (median, ulnar) which demonstrate rather stable and constant evoked responses, but may be problematic with pure sensory nerves such as the lateral femoral cutaneous nerve (LFCN) which generates less stable evoked responses. To date, this

From the Departments of Anesthesiology, ${ }^{*}$ and Orthopedic and Traumatologic Surgery, † Hôpital Erasme, Université Libre de Bruxelles, Brussels, Belgium.

Address correspondence to: Dr. Jean Corentin Salengros, Université Libre de Bruxelles, Department of Anesthesiology, CUB Hôpital

Erasme, 808, route de Lennik, 1070 Brussels, Belgium. Phone: +32-2-555-39-19; Fax: +32-2-555-43-63;

E-mail: jean.salengros@ulb.ac.be

Support for this work has been provided solely from institutional and departmental sources.

Accepted for publication June 7, 2005.

Revision accepted July 27, 2005. 
monitoring modality has remained underused, mainly, because of the expertise needed to interpret the data.

After obtaining written patient consent for possible publication of personal information in a case report according to local institutional guidelines, we present two cases of on-line, intraoperative, peripheral nerve somatosensory evoked potentials (SSEP) monitoring that proved helpful for the surgeon, and later functionally for the patient, during difficult surgical dissection.

\section{Case 1}

Several months prior to his scheduled surgery, a 44-yrold male sustained a medio-diaphyseal fracture of the right clavicle during a sport accident. His injury was managed initially with the use of a splint.

On several occasions after the accident, he complained of right thumb hypoesthesia and was readmitted to hospital for further evaluation. Upon clinical examination, the patient described hypoesthesia of the right thumb, dysesthesia in the second, third and fourth right fingers. A secondary evaluation included magnetic nuclear resonance imaging (MRI) of the shoulder and clavicle region, sensory conduction velocity, and electromyography (EMG). Conduction velocity studies showed no response over the ulnar nerve distribution, while for the median nerve, amplitude was decreased to $4.3 \mu \mathrm{V}$. Electromyography of the right abductor digiti minimi and pollicis brevis muscles showed some fibrillation, and more importantly, a tattered and polyphasic aspect of motor unit potentials. The different investigations were consistent with the diagnosis of a pseudo-arthrosed clavicle with a possible entrapment of the plexus, probably without trunk disruption. Findings were mainly limited to median and ulnar nerves. Surgical exploration of the infraclavicular region was proposed and accepted by the patient.

The patientwas American Society of Anesthesiologists (ASA) physical status I, weighing $80 \mathrm{~kg}$ and $165 \mathrm{~cm}$ in height. He was premedicated with alprazolam 0.5 $\mathrm{mg}$ po on the evening before and again two hours before induction of anesthesia. Anesthesia consisted of a total iv technique (propofol and sufentanil), titrated to achieve a stable concentration (in order to interfere as little as possible with the SSEP recordings), in oxygen/air $(50 \% / 50 \%)$ mixture without any neuromuscular blocking agent.

We proposed to both the patient and the surgeon our plan to monitor median and ulnar nerve SSEP during surgical dissection, allowing us to detect possible enhancement in nerve conduction corresponding to an improvement of the profile (amplitude and latencies) of existing evoked waves, as soon as the nerve structures were surgically released.

Based on clinical twitches, two sets of silver/silver chloride pediatric surface electrodes (3M Red Dot ${ }^{\mathrm{TM}}$ 2269 T, St Paul, MN, USA) were placed to stimulate median and ulnar nerves at the wrist (cathode proximal, anode distal). They were connected to the electrical stimulator of an Epoch 2000 ${ }^{\mathrm{TM}}$ (Axon Systems Inc, San Francisco, CA, USA) machine. Somatosensory evoked potentials were recorded on the scalp using a single channel cephalic montage, based on the ten to 20 conventions (reference or positive electrode on the right auricular point, and active or negative electrode on C' 3 on the scalp over the primary sensory cortex) and based on the average of 500 sweeps. Low and high bandpass filters were fixed at $2 \mathrm{~Hz}$ and $750 \mathrm{~Hz}$ respectively, while a notch filter $(50 \mathrm{~Hz})$ was active. A squared electrical stimulus, $0.2 \mathrm{msec}$ long, was continuously delivered to the patient at a rate of 7.1 Hz. Stimulation intensity was increased progressively, in $1 \mathrm{~mA}$ by $1 \mathrm{~mA}$ steps, until we were able to observe muscular twitches. Clinical intensity thresholds were fixed to $10 \mathrm{~mA}$ for the median nerve and $12 \mathrm{~mA}$ for the ulnar nerve, respectively, to obtain stable and efficient twitches. Above these values, the profile and structure of the evoked potentials (mainly amplitude) were not enhanced. At that time, for both median and ulnar nerves, a main potential around $20 \mathrm{msec}$ was observed, corresponding to the physiological N20. This corresponds to the initial electrical response in the somesthetic cortex (posterior to the central scissure) after peripheral nerve stimulation and relates the integrity of the nerve conduction from the periphery to the brain. In this case, some delay and a lower amplitude in reference to physiological values ${ }^{6}$ were observed (Figure 1).

These abnormalities were the result of plexus entrapment. Accordingly, intensities of stimulation were fixed for each nerve, and the corresponding evoked responses were considered as baselines to be compared to later ones.

Upon surgical dissection of the delto-pectoral groove, it became clear that the subclavian muscle had been damaged and fibrosed by trauma. It subsequently entrapped the brachial plexus under the pseudoarthrosed clavicle. At that time, the surgeon could not distinguish between fibrous and nervous tissue as he started to dissect the region under microscopy.

After approximately $70 \mathrm{~min}$ of careful but nearly blind dissection, the SSEP changed progressively during a period of approximately five to six minutes, firstly in the ulnar and secondly in the median nerve, both within four to five minutes. At that time, the evoked 


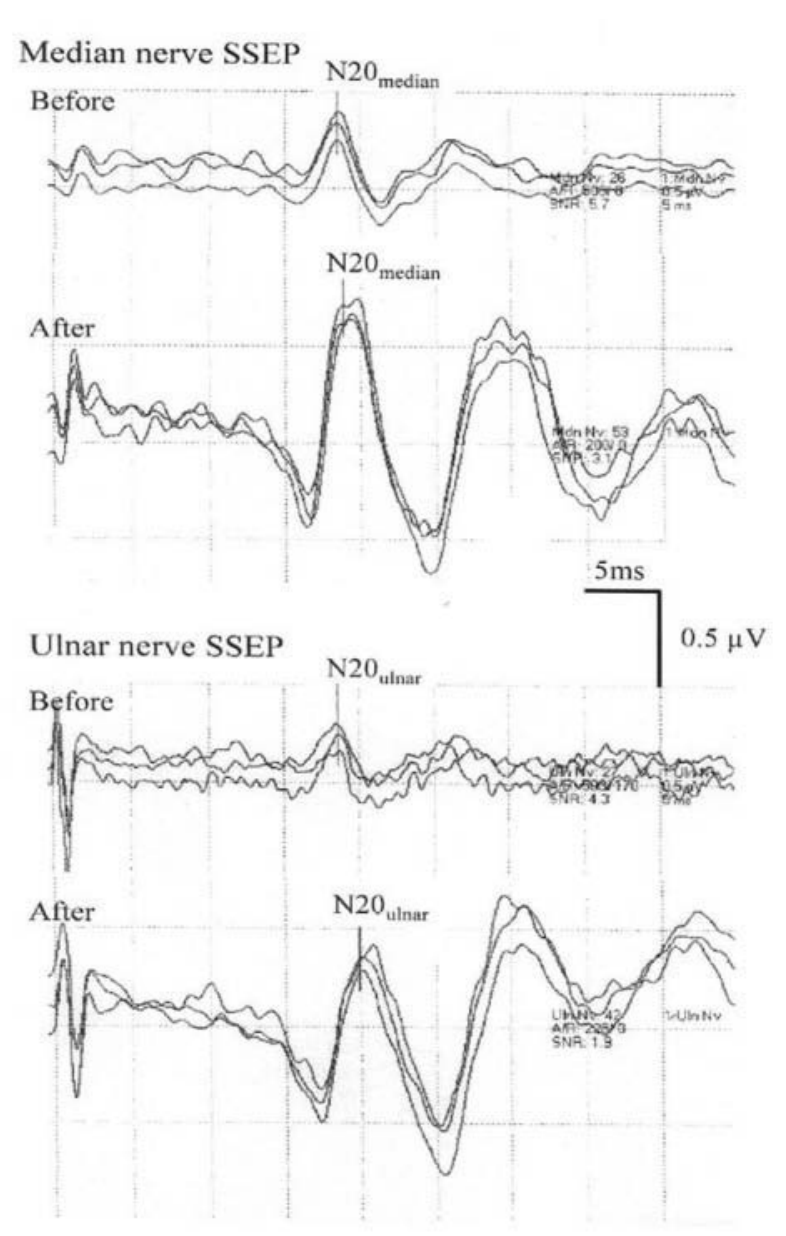

FIGURE 1 Cortical SSEP (presented as the mini-stack of the three last recorded traces) of median (above) and ulnar (bottom) nerves, before and after surgical dissection. Before surgery, stable, structured but low amplitude potentials were obtained from a stimulation intensity threshold of $10 \mathrm{~mA}$ for median and $12 \mathrm{~mA}$ for ulnar nerve. $\mathrm{N} 20_{\text {median }}$ $(18.95 \mathrm{msec}-0.26 \mu \mathrm{V})$ and $\mathrm{N} 20_{\text {ulnar }}(18.97 \mathrm{msec}-0.18$ $\mu \mathrm{V})$, respectively, were detectable, while another very low amplitude negative potential could be individualized at approximately 25 to $26 \mathrm{msec}$. After $70 \mathrm{~min}$ of surgery, long-term SSEP changes were reversed during the progressive release of the respective nerve trunks of the brachial plexus from sclerosis and entrapment. Reversal consisted mainly of the brisk increase in SSEP amplitude. N20 $(19.30 \mathrm{msec}, 0.64 \mu \mathrm{V})$ and $\mathrm{N} 20_{\text {ulnar }}(20.75 \mathrm{msec}, 0.42 \mu \mathrm{V})$ were easily recognizable, though slightly delayed. At that time, successive high amplitude potentials were measurable at $24.55 \mathrm{msec}(-0.67 \mu \mathrm{V}), 29.30 \mathrm{msec}(0.43 \mu \mathrm{V}), 35.75$ $\operatorname{msec}(-0.38 \mu \mathrm{V})$ and $40.35 \mathrm{msec}(0.14 \mu \mathrm{V})$ for median nerve and at $25.15 \mathrm{msec}(-0.15 \mu \mathrm{V}), 29.5 \mathrm{msec}(0.68 \mu \mathrm{V})$, $35.6 \mathrm{msec}(-0.17 \mu \mathrm{V})$ and $41.4 \mathrm{msec}(0.4 \mu \mathrm{V})$ for ulnar nerve. SSEP $=$ somatosensory evoked potentials. potentials improved mainly in terms of amplitude (Figure 1). They were also more structured, since six large and stable waves could now be measured (Figure 1). After $110 \mathrm{~min}$, surgery ended, based upon inspection of the surgical field, but, more importantly, as a result of the stability of the SSEP traces. The neurological symptoms disappeared completely a few days postoperatively.

\section{Case 2}

A 61-yr-old male patient was referred to the hospital for further evaluation of numbness of the lateral part of the left thigh. The patient had a history of bilateral inguinal hernia repair. The patient had stopped smoking $20 \mathrm{yr}$ previously and alcohol consumption was negligible. He described also a burning-like pain point on the iliac spine, anterior superior (ASIS). Antiepileptic, anti-depressor drugs and gabapentin were unsuccessful in relieving the symptoms. Pain relief could only be achieved by repeated local anesthetic infiltrations ( $2 \%$ lidocaine $5 \mathrm{~mL}$ ) at the ASIS. On physical examination, the patient had an insensibility of the lateral part of the left thigh. Electromyography of the different muscles (peroneus longus, medial head of gastrocnemius, tibialis anterior and quadriceps femoris) of the lower limb was normal. Magnetic nuclear resonance imaging of the lumbar column was normal. An MRI performed on the inguinal region showed possible extrinsic fibrous compression responsible for the painful syndrome reported by the patient. At that time, a surgical release of the LFCN was proposed and accepted by the patient.

The subject was ASA physical status II, weighing $75 \mathrm{~kg}$ and $172 \mathrm{~cm}$ in height. Preoperative tests were normal. Premedication consisted of alprazolam 0.5 $\mathrm{mg} p o$ on the evening and two hours before surgery. Anesthesia consisted of a total iv technique (propofol and sufentanil), titrated to achieve a stable plasma concentration in order not to interfere with SSEP recordings, in an oxygen/air $(50 \% / 50 \%)$ mixture without any neuromuscular blocking drug. Based on our initial clinical experience with this kind of intraoperative monitoring (mainly stimulation of mixed nerves), we proposed to elicit LFCN specific SSEP (recorded using a conventional bipolar cephalic montage) by stimulating transcutaneously the centre of the cutaneous nerve supply zone in order to detect, during dissection, new evoked potentials or measure the increase in amplitude of eventually existing ones.

After induction of anesthesia, two silver/silver chloride pediatric surface electrodes (3 M Red Dot тм 2269 T, St Paul, MN, USA) were attached around the theoretic mid-point between the ASIS and the 


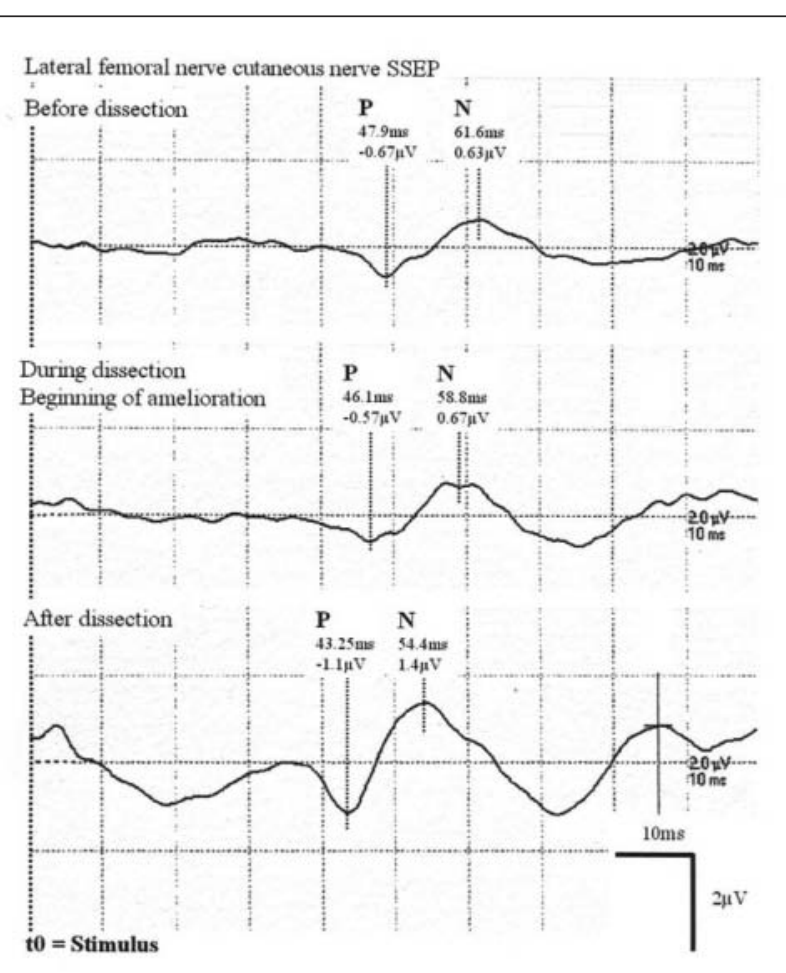

FIGURE 2 Cortical SSEP of the lateral femoral cutaneous nerve, before (upper), during (middle) and at the end of surgery (bottom). Before surgery, a low amplitude trace occurred when stimulation intensity was $22 \mathrm{~mA}$. The optimal pre-incision evoked potential (upper) was elicited by stimulation intensity of $25 \mathrm{~mA}$. Only a downward deflection $(\mathrm{P})$, at $47.9 \mathrm{msec}(-0.67 \mu \mathrm{V})$, followed by an upward one $(\mathrm{N})$, at $61.6 \mathrm{msec}(0.63 \mu \mathrm{V})$, were readable. After 45 min, during the surgical dissection (middle), the amplitude of SSEP progressively increased in ten to $12 \mathrm{~min}$, associated to the beginning of the finish of the conduction block by surrounding fibrosis to the LFCN. P was measured at $46.1 \mathrm{msec}(-0.57 \mu \mathrm{V})$ while $\mathrm{N}$ at $58.8 \mathrm{msec}(0.67 \mu \mathrm{V})$. In total, five waves were gradually more and more easily observable and measurable. After $70 \mathrm{~min}$, at the end of surgery (bottom), the amplitude of the LFCN SSEP has increased matching probably, at least, partial reversal of long-term changes induced by the extrinsic compression. $\mathrm{P}$ was retrieved at $43.2 \mathrm{msec}(-1.1 \mu \mathrm{V})$ and $\mathrm{N}$ at $54.4 \mathrm{msec}$ $(1.4 \mu \mathrm{V})$. SSEP $=$ somatosensory evoked potentials, LFCN = lateral femoral cutaneous nerve.

lateral knee joint line (approximatively 25 to $26 \mathrm{~cm}$; positive pole distally and negative pole proximally) and connected to the electrical stimulator of an Epoch $2000^{\mathrm{TM}}$ (Axon Systems Inc, San Francisco, CA, USA) machine.
In accordance with a recent report, ${ }^{8}$ SSEP were recorded on the scalp with a single channel cephalic montage using ten to 20 conventions (reference or positive electrode on Fpz, and active or negative electrode on C'z on the scalp over the primary sensory cortex) based on the average of 500 sweeps. Nevertheless, the bandpass of the low and high filters was narrower than the one used by Seror $(10-2000 \mathrm{~Hz})$, fixed at 2 to 750 $\mathrm{Hz}$ respectively, because of operating theatre technical conditions. A notch filter $(50 \mathrm{~Hz})$ was active. Squared electrical stimulus, $0.2 \mathrm{msec}$ long was continuously delivered to the patient at a rate of $5.1 \mathrm{~Hz}$. Initial stimulation intensity was fixed at $5 \mathrm{~mA}$ and was increased progressively, $1 \mathrm{~mA}$ by $1 \mathrm{~mA}$. At least one average was recorded for each step of stimulation intensity. Before $22 \mathrm{~mA}$, no structured potentials could be observed but, at this threshold, a response occurred and at least latencies and amplitudes could now be measured. To improve trace quality and refine ability to measure different spikes, we increased intensity to $25 \mathrm{~mA}$ (Figure 2 ). The intensity was then fixed because, above this threshold, the potentials were now stable without changes or improvement in their profile.

This evoked response was thus considered as baseline to compare to subsequent ones. On this trace, a biphasic potential could be identified, but with low amplitude in reference to physiological SSEP values (Figure 2). From $12 \mathrm{~mA}$, muscular twitches induced by electrical stimulation were observed in the vastus lateralis muscle and seemed to peak at $20 \mathrm{~mA}$.

Surgical exploration confirmed our initial impression that the LFCN had been entrapped in postoperative fibrosis after the inguinal hernia repair. The surgeon could not determine the difference between fibrosis and nervous tissue. During stable anesthesia and without any changes which could have possibly influenced SSEP recording, $45 \mathrm{~min}$ after incision, during careful but nearly blind dissection, the evoked potentials began to change progressively during a four-average long period (approximately 10-12 min). The evoked potentials improved both in terms of amplitude and latency (Figure 2). They were more structured, since five large and stable waves could now be measured.

After $70 \mathrm{~min}$, surgery ended based mainly upon stability of SSEP traces. From the time of surgery, the patient remained asymptomatic.

\section{Discussion}

As a result of various mechanisms (fracture, extrinsic compression, entrapment, disruption, stretching) peripheral nerve structures can be damaged and may need surgical exploration. Typically, patients undergo 
surgery without minimal or no intraoperative neurological monitoring with exception of local electrostimulation of neural trunks during dissection of peripheral nerves surroundings. These two different cases illustrate the ability to use specific SSEP from different, anatomically intact nerves, (mixed or purely sensory) involved in complex lesions. This may guide evaluation of nerve function intraoperatively, during and after dissection. Moreover, this monitoring may also potentially predict functional recovery.

In the case of plexus injury, the improvement in cortical SSEP after either median or ulnar nerve stimulation are consistent with the release of intact nerve structures from local entrapment. The significant increase in amplitude (from approximately $0.2-1 \mu \mathrm{V}$ ) of more structured potentials (four to six waves) is consistent with enhanced electrical cortical inputs following progressive improvement in electric transmission. Alternatively, basic intraoperative EMG, and particularly continuous free-running electromyographic monitoring, ${ }^{9}$ is considered equally useful to detect possible surgical induced nerve damage (nerve root or cranial nerve monitoring during spine or skull base surgery, for instance). Nevertheless, while the EMG seems to be well adapted to evaluate the integrity of neural structures against potential surgical damage, the SSEP has the potential to improve evaluation of nerve conduction during difficult dissection. Nevertheless, mechanical trauma is less likely to evoke neurotonic discharges from abnormal motor nerves ${ }^{10}$ and, in addition, EMG may miss further intraoperative injury to nerves previously damaged by a non-surgical underlying disease process. Ultimately, the best clinical prospect could be to combine SSEP and EMG, rather than excluding one technique from another. ${ }^{11}$

Regarding the LFCN, one limitation lies in the fact that this nerve is purely sensory, precluding the use of usual motor nerve stimulation patterns. Nevertheless, LFCN cutaneous supply zone stimulation is possible $^{7,12}$ according to techniques published previously, ${ }^{13}$ and recently refined. ${ }^{8}$ Moreover, others have demonstrated the ability to determine the extent of the LFCN cutaneous supply zone (by needle stimulation) and the saphenous nerve cutaneous supply zone (by transcutaneous stimulation). ${ }^{14,15}$ These stimulation modalities could be helpful in this particular situation, in order to determine the optimal location to apply the electrical cutaneous stimulator. Unfortunately, the patient must be awake and conscious. Perhaps, preoperative transcutaneous stimulation of sensory nerve trunks could be considered, as opposed to measuring possible cutaneous nerve supply zones exclusively on an anatomical basis (measurement from the ASIS to the lat- eral knee joint line in the case of the LFCN). Another important limitation is the duration of the stimulus required. Its duration $(0.2 \mathrm{msec})$ is similar to the one described by Seror et al. ${ }^{8}$ and corresponds to sensory

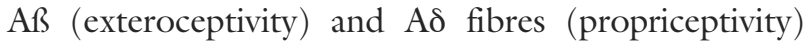
respective rheobases $(0.15$ and $0.17 \mathrm{msec}) .{ }^{16}$ This can be important in order to ensure exclusivity of "sensory fibre" stimulation, to elicit a more specific response. In this case, it required $22 \mathrm{~mA}$ to elicit a potential (upper evoked potential in Figure 2), similar to previously published data. ${ }^{7,8}$ It is possible that increasing the stimulus duration to $0.4 \mathrm{msec}$ might stimulate sensory fibres more specifically. However, inter-individual variability in stimulation intensity thresholds must also be considered. In the case described here, the response witnessed most likely originates from the LFCN and not from the femoral nerve, as no potentials were recorded when the twitches occurred (from $12 \mathrm{~mA}$ ), as usually observed in current practice when mixed nerve stimulation is used.

In these two cases, the long-lasting SSEP changes are consistent with a significant reduction of amplitude in early cortical responses of the investigated nerves $(0.26,0.18$ and $0.67 \mu \mathrm{V}$ respectively). Expressed differently, the latencies of median and ulnar nerves are normal but that of the LFCN is delayed. The reversibility of the SSEP changes is always contrasted: on one hand the brisk increase of the amplitude, and on the other, the latencies are slightly delayed in median and ulnar nerve and reduced in LFCN. Two hypotheses can explain this phenomenon. The increase in SSEP amplitude could relate the on-line effect of the surgical removal from the extrinsic compression, while the lower latency reactivity could be explained by the persistence of poor nerve conduction from possible intraneural chronic compression. These latter changes are nevertheless reversible, but may require weeks or months to recover.

In conclusion, intraoperative SSEP monitoring may be effective in guiding surgical release of entrapped peripheral nerves. Accurate intraoperative electrophysiological assessment of these structures allows the medical team to distinguish between nervous and other tissues.

Even though this particular monitoring requires a significant amount of expertise and requires further clinical evaluation, it may become a standard in the future for complex limb surgery, and potentially, predict functional outcome.

\section{References \\ 1 Grundy BL. Intraoperative monitoring of sensory- evoked potentials. Anesthesiology 1983; 58: 72-87.}


2 Papastefanou SL, Henderson LM, Jollyon Smith N, Hamilton A, Webb JK. Surface electrode somatosensory-evoked potentials in spinal surgery. Implications for indications and practice. Spine 2000; 25: 2467-72.

3 Luk KD, Hu $\Upsilon$, Wong $\Upsilon W$, Cheung KM. Evaluation of various evoked potential techniques for spinal cord monitoring during scoliosis surgery. Spine 2001; 26: 1772-7.

4 Danesh-Clough T, Taylor P, Hodgson B, Walton M. The use of evoked EMG in detecting misplaced thoracolumbar pedicle screws. Spine 2001; 26: 1313-6.

5 Guérit JM, Verbelst R, Rubay J, Khoury G, Matta A, Dion $R$. Multilevel somatosensory evoked potentials (SEPs) for spinal cord monitoring in descending thoracic and thoraco-abdominal aortic surgery. Eur J Cardiothorac Surg 1996; 10: 93-104.

6 Yiannikas $C$. Short-latency somatosensory evoked potentials in peripheral nerve lesions, plexopathies, and radiculopathies. In: Chiappa KH (Ed.). Evoked Potentials in Clinical Medicine, 3rd ed. Philadelphia: Lippincott-Raven; 1997: 425-54.

7 Eisen $A$. The use of somatosensory evoked potentials for the evaluation of the peripheral nervous system. Neurol Clin 1988; 6: 825-38.

8 Seror P. Somatosensory evoked potentials for the electrodiagnosis of meralgia paresthetica. Muscle Nerve 2004; 29: 309-12.

9 Holland NR. Intraoperative electromyography. J Clin Neurophysiol 2002; 19: 444-53.

10 Holland NR, Lukaczyk TA, Riley LH 3rd, Kostuik

$J P$. Higher electrical stimulus intensities are required to activate chronically compressed nerve roots. Implications for intraoperative electromyographic pedicle screw testing. Spine 1998; 23: 224-7.

11 Krassioukov AV, Sarjeant R, Arkia H, Fehlings $M G$. Multimodality intraoperative monitoring during complex lumbosacral procedures: indications, techniques, and long-term follow-up review of 61 consecutive cases. J Neurosurg Spine 2004; 3: 243-53.

12 Aminoff MJ, Eisen AA. AAEM minimonograph 19: somatosensory evoked potentials. Muscle Nerve 1998; 21: 277-90.

13 Butler ET, Johnson EW, Kaye ZA. Normal conduction velocity in the lateral femoral cutaneous nerve. Arch Phys Med Rehabil 1974; 55: 31-2.

14 Shannon J, Lang SA, Yip RW, Gerard M. Lateral femoral cutaneous nerve block revisited. A nerve stimulator technique. Reg Anesth 1995; 20: 100-4.

15 Stone BA. Transcutaneous stimulation of the saphenous nerve to locate injection site (Letter). Reg Anesth Pain Med 2003; 28: 153-4.

16 Pither CE, Raj PP, Ford DJ. The use of peripheral nerve stimulators for regional anesthesia. A review of experimental characteristics, technique, and clinical implications. Reg Anesth 1985; 10: 49-58. 